\title{
MIGRAÇÃO LATERAL DA DESEMBOCADURA DO RIO ITAPOCÚ, SC, BRASIL: EVOLUÇÃO MORFOLÓGICA E CONDICIONANTES FÍSICAS
}

\author{
Gabriela Freire Cassiano ${ }^{1}$ e Eduardo Siegle ${ }^{2}$ \\ Recebido em 9 setembro, 2009 / Aceito em 1 julho, 2010 \\ Received on September 9, 2009 / Accepted on July 1, 2010
}

\begin{abstract}
Inlets are highly dynamic environments subjected to the complex interaction between stabilizing and destabilizing factors. Depending on this interaction, inlets have a tendency to migrate along sandy barriers. One of the most effective mechanisms for transporting sediment alongshore and consequently controlling the migration of inlets, are currents generated by waves approaching the coast at an angle. The motivation of this study is to better understand the morphodynamic behavior of the Itapocú inlet, at the northern Santa Catarina (SC) coast. The morphology of the sandy spits that enclose the inlet was obtained from morphological surveys conducted with the use of DGPS. To analyze the wave refraction the numerical model MIKE 21 SW has been applied to the region. Boundary conditions have been set based on a one-year long database (2002) and predicted waves for the studied period. The model output has been used to estimate the potential longshore drift in the region. Results show the migration of the inlet to the north during the analyzed period, with higher migration rates during winter and summer. Waves incoming from the south are the most influenced by the refraction process, while the less refracted waves are those coming from the east. The net longshore drift obtained when using the 2002 database is southwards, presenting slight inversions during autumn. When using the predicted wave data for the studied period, the potential longshore drift is dominated by northward direction, in agreement with the observed inlet migration. The Itapocú river discharge does not present any relation with the observed inlet migration rates, although there seems to be a relation with the seasonal channel width variability. The surveyed morphological evolution is well related to the potential longshore drift for the 2004/2005 waves, indicating that during the monitored period, the northwards inlet migration is being controlled by the wave generated longshore drift.
\end{abstract}

Keywords: inlet dynamics, wave refraction, longshore drift.

RESUMO. Desembocaduras são ambientes bastante dinâmicos e sujeitos à complexa interação entre fatores estabilizadores e desestabilizadores. Dependendo dessa interação, desembocaduras podem apresentar a tendência de migração ao longo de barreiras arenosas. Um dos mecanismos mais eficientes de transporte de sedimento paralelo à costa, e consequentemente migração de canais, são as correntes Iongitudinais geradas pelas ondas se aproximando obliquamente à costa. A motivação do presente trabalho é entender o comportamento morfodinâmico do sistema de desembocadura do rio Itapocú, localizado no centro-norte de Santa Catarina (SC), frente aos processos forçantes que atuam na sua migração ao longo da linha de costa. A morfologia dos pontais arenosos foi obtida a partir de levantamentos morfológicos com 0 uso de DGPS. Para analisar a refração de ondas foi utilizado o modelo numérico MIKE 21 SW, sendo considerados como condições de contorno os dados de ondas referentes ao ano de 2002 e os dados de ondas previstos referentes ao período de coleta. Os dados de saída do modelo foram utilizados para estimar a deriva litorânea potencial na região. Os resultados morfológicos obtidos demonstraram uma migração da desembocadura para o norte durante o período analisado, sendo mais intenso durante 0 inverno e o verão. Ondas incidentes do quadrante sul sofreram mais o fenômeno da refração e as ondas de leste apresentaram menor variação angular ao se aproximarem à costa. A deriva litorânea potencial anual para os dados de ondas de 2002 apresentou sentido norte-sul, com inversão de sentido durante 0 outono. Utilizando os dados de ondas previstas para o período dos levantamentos, a deriva litorânea potencial estimada apresentou sentido sul-norte, concordando com a migração observada. Na região próxima a desembocadura, nos pontais arenosos, a deriva potencial apresentou direção para o norte durante todas as estações. Os dados de descarga fluvial não apresentaram influência na migração do canal, porém apresentaram uma relação com a largura do mesmo sazonalmente. Os dados de morfologia juntamente com os dados de deriva litorânea referentes às ondas de 2004/2005 mostraram claramente a migração do canal para o norte sendo a deriva a principal contribuinte para a migração da desembocadura.

Palavras-chave: dinâmica de desembocadura, refração de ondas, deriva litorânea.

\footnotetext{
1 Pós-graduação em Oceanografia Química e Geológica, Instituto Oceanográfico da Universidade de São Paulo, Praça do Oceanográfico, 191, Cidade Universitária, 05508-120 São Paulo, SP, Brasil - E-mail: gabifcassiano@hotmail.com

2 Instituto Oceanográfico da Universidade de São Paulo, Praça do Oceanográfico, 191, Cidade Universitária, 05508-120 São Paulo, SP, Brasil - E-mail: esiegle@usp.br
} 


\section{INTRODUÇÃo}

Desembocaduras estuarinas são bastante frequentes ao longo da linha de costa, sendo importantes para a troca de materiais entre 0 continente e 0 oceano. Devido à sua alta importância ecológica e econômica e à influência que exercem sobre a zona costeira adjacente, as desembocaduras têm sido objeto de muitos estudos dentro das ciências costeiras e da engenharia (Mehta, 1996). Estes sistemas têm grande influência sobre 0 balanço sedimentar das regiões costeiras, afetando a estabilidade das praias adjacentes (FitzGerald, 1988; Fenster \& Dolan, 1996; Siegle et al., 2004, 2007). Os corpos sedimentares associados às desembocaduras, como os deltas de maré enchente e vazante, são importantes reservatórios temporários e permanentes de sedimentos. Adicionalmente, os deltas de maré vazante têm grande influência na distribuição da energia de ondas. Esta feição protege a linha de costa das ondas incidentes e define os padrões de transporte de sedimentos.

As principais forçantes que controlam a geometria do canal e dos corpos sedimentares adjacentes são a altura da maré, 0 nível de energia das ondas, 0 aporte de sedimentos, a magnitude e frequência de tempestades, 0 aporte de água doce e a batimetria local (FitzGerald, 1996; Kana et al., 1999). Segundo Komar (1996), essas variáveis associadas às desembocaduras, tornam-nas em um dos ambientes mais complexos da zona costeira. As desembocaduras podem ser consideradas sistemas morfodinâmicos, funcionando através da interação dos três componentes principais: dinâmica de fluidos, transporte de sedimentos e mudanças morfológicas. A dinâmica de fluidos é induzida pela entrada de energia no sistema através de correntes e ondas e é influenciada pela topografia. Este ajuste mútuo da topografia e da dinâmica de fluídos é interligado pelo transporte de sedimento ao longo do tempo. Gradientes no transporte de sedimento resultam em regiões de erosão e deposição alterando a morfologia. Essa nova morfologia leva a mudanças na hidrodinâmica que pode então reforçar ou amenizar tais mudanças morfológicas.

Desembocaduras, quando posicionadas em barreiras arenosas, apresentam uma tendência natural de migrar, um resultado dos processos sedimentares em função das condições hidrodinâmicas únicas nesses ambientes (Aubrey \& Speer, 1984). Em função de sua importância, a capacidade de entender e prever 0 comportamento de desembocaduras e linha de costa adjacente é fundamental para o seu correto manejo. Os processos em ambientes de energia mista são bastante sensíveis as condições forçantes externas. Desta forma, mudanças nas condições naturais ou induzidas por atividades antrópicas podem resultar em grandes impactos no sistema. A necessidade de melhor enten- der e prever o comportamento desses ambientes complexos e dinâmicos levou recentemente ao desenvolvimento de modelos numéricos de seu comportamento. Através da aplicação desses modelos, tornou-se possível estimar muitos dos processos atuantes (ondas, correntes, transporte de sedimento, mudanças morfológicas) que ocorrem nesses ambientes (De Vriend, 1996).

0 objetivo do presente trabalho é a análise do comportamento dinâmico da desembocadura do rio Itapocú, SC, e a compreensão dos processos que controlam a sua migração ao longo de um segmento do litoral norte de Santa Catarina.

\section{ÁREA DE ESTUDO}

A desembocadura do rio Itapocú (Fig. 1) está localizada no norte do estado de Santa Catarina, sendo a divisa entre os municípios de Barra Velha e Araquari. 0 rio Itapocú deságua na porção central de uma laguna estreita e paralela à linha de costa com cerca de $10 \mathrm{~km}$ de extensão. A desembocadura da laguna migra ao longo da barreira arenosa, podendo a migração ser para norte ou para sul em relação à região de deságue do rio na laguna. A descarga fluvial do rio é medida diariamente desde 1940, e extrapolada a partir de dados da estação do rio Jaraguá (aproximadamente $60 \mathrm{~km}$ da desembocadura), que representa cerca de $27 \%$ de sua bacia de drenagem, é de aproximadamente $77 \mathrm{~m}^{3} . \mathrm{s}^{-1}$ (Schettini \& Carvalho, 1998). A hidrodinâmica do sistema lagunarestuarino do rio Itapocú é apresentado por Abreu et al. (2010).

0 clima na área de estudo apresenta características subtropicais, estando sob o controle do centro de alta pressão do Anticiclone do Atlântico Sul (Monteiro, 1968; Nobre et al., 1986; Nimer, 1989). 0 período de maior pluviosidade encontra-se entre dezembro e março, e de menor entre abril e julho. A média anual de pluviosidade na bacia de drenagem é de cerca de $2.200 \mathrm{~mm}$ (GAPLAN - Atlas de Santa Catarina, 1986).

A maré no litoral norte-catarinense é semidiurna, com variação de 0,8 m a 1,2 m (Schettini \& Klein, 1997). A influência de fatores meteorológicos é bastante importante, podendo provocar sobrelevações do nível do mar na ordem de 0,8 m em relação à maré astronômica (Truccolo, 1998).

Com base em dados medidos ao longo do ano de 2002 ao largo da Ilha de Santa Catarina, Araújo et al. (2003) definiram 0 clima de ondas para o litoral catarinense. As ondas na região apresentam incidência do quadrante leste durante a primavera $e$ leste e sul durante 0 verão, com alturas e períodos similares para ambas as estações, $1,25 \mathrm{~m}$ e $8 \mathrm{~s}$, respectivamente. No outono, ocorre predominância de ondas do quadrante sul com altura de 1,5 m e no inverno, predominância de leste e sul, com altura variando entre $1,25 \mathrm{~m}$ e 2,5 $\mathrm{m}$. 0 período dominante para as 


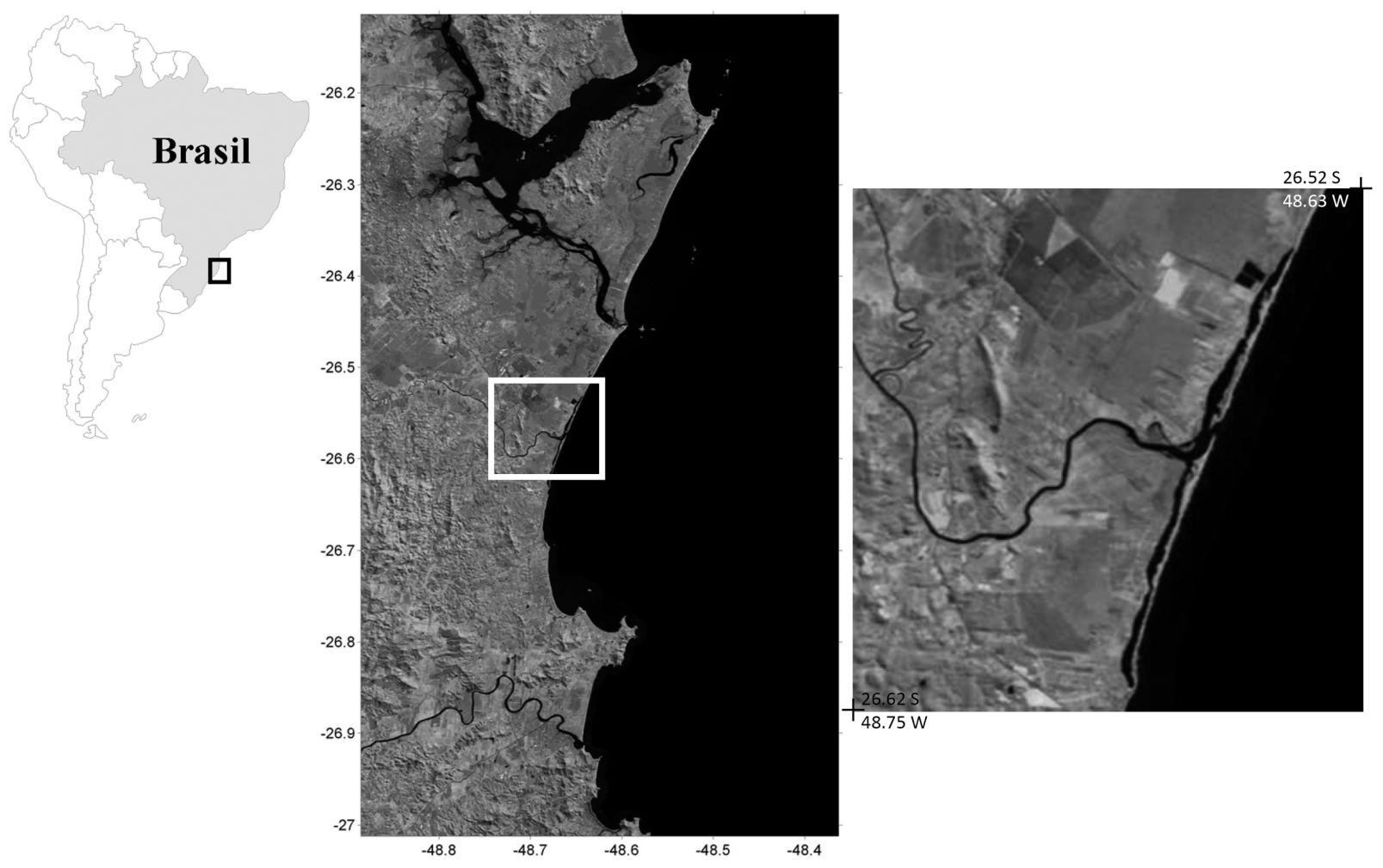

Figura 1 - Localização da área de estudo. A imagem no centro representa o litoral centro-norte de SC e a imagem à direita a região da desembocadura do rio Itapocú (Imagens Landsat, fonte: Embrapa (Miranda, 2005)).

duas estações foi de $12 \mathrm{~s}$. Segundo Araújo et al. (2003), eventos de ondas com maior altura $(4,0 \mathrm{~m})$ podem ocorrer em todas as estações. 0 inverno foi a estação mais energética, tendo 0 maior valor médio de altura de onda e maior desvio padrão se comparado a outras estações, isso ocorreu pela passagem de algumas frentes frias e a ocorrência de ventos mais intensos. Com base em onze anos de dados de reanálise do modelo global NWW3, Pianca et al. (2010) definiram o clima de ondas e a força das ondas ao largo da costa brasileira, indicando para a região sul do Brasil a dominância de ondas de sul e nordeste. As ondas do quadrante sul, mais energéticas durante os meses de inverno, controlam a variabilidade sazonal da força das ondas na região.

\section{A migração do canal}

Através do levantamento de fotografias aéreas da região e dados históricos coletados com moradores locais, Piérri (2005) apresenta uma sequência histórica da migração da desembocadura ao longo da barreira arenosa. 0 sumário dessa evolução está representado na Figura 2, com a indicação da posição do canal ao Iongo das últimas décadas. A primeira informação quantitativa da posição da desembocadura é de 1957, quando se encontrava aproximadamente $500 \mathrm{~m}$ ao norte da foz do rio. 0 canal continuou migrando em direção ao norte e em 1966 se encontrava a $800 \mathrm{~m}$ da foz do rio. 0 próximo registro mostra a desembocadura mais ao sul, a aproximadamente $300 \mathrm{~m}$ ao norte da foz do rio. Essa posição provavelmente indica uma migração ao norte a partir de uma abertura artificial do canal para melhorar 0 escoamento das águas do rio em função de cheias no início da década de 70, segundo informações de moradores locais. 0 mesmo ocorreu em 1983, quando em função das grandes cheias na região foi aberto artificialmente 0 canal em frente à foz do rio. Registros fotográficos mostram que após essa abertura, o canal migrou para o sul por um curto período, seguido novamente pela migração ao norte. Em 1995 o canal se encontrava aproximadamente em frente à foz do rio (Fig. 2). Entre 1995 e 2005, 0 canal migrou para 0 norte com uma taxa de aproximadamente $100 \mathrm{~m}$ por ano.

\section{MÉTODOS}

\section{Morfologia}

Para analisar a morfologia dos pontais arenosos foram realizados cinco levantamentos entre agosto de 2004 e junho de 2005 através da utilização de um sistema de posicionamento global diferencial 
(DGPS) que cobriram o entorno do canal, nos pontais arenosos ao norte e ao sul. Os levantamentos ocorreram nos dias 05 de agosto, 29 de outubro e 02 de dezembro de 2004 e 20 de abril e 03 de junho de 2005. Os dados obtidos com o DGPS foram interpolados no software Surfer (Golden Software). A partir da confecção das malhas de dados interpolados foram obtidos diagramas tridimensionais, para os cinco levantamentos, permitindo a melhor comparação entre os levantamentos.

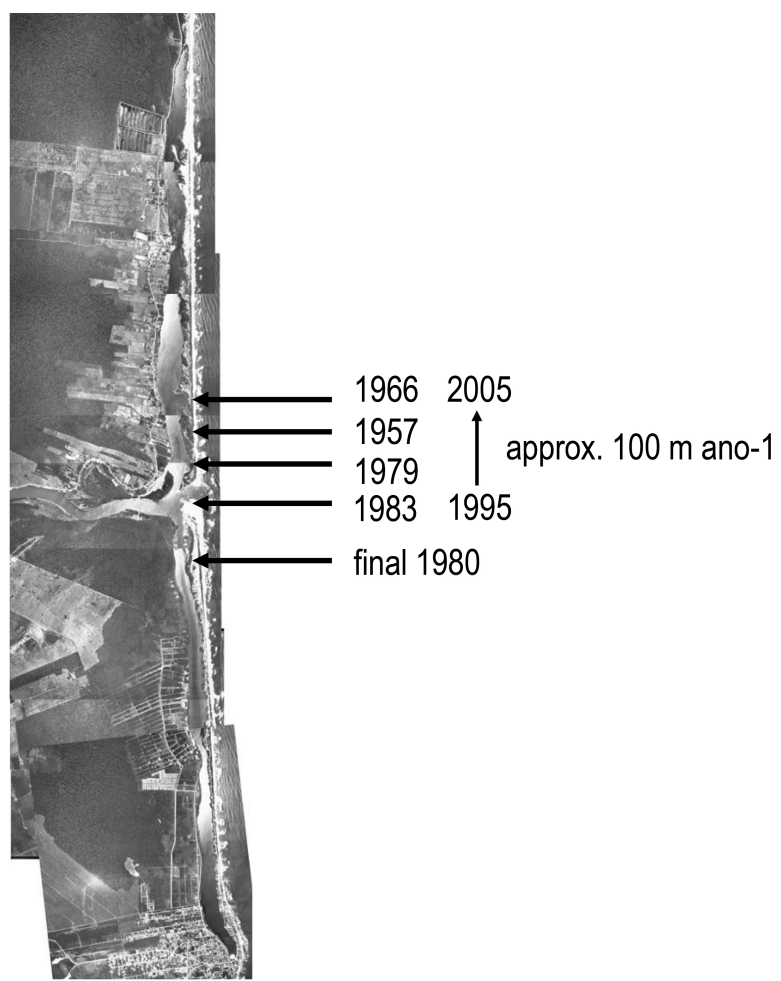

Figura 2 - Histórico da desembocadura do rio Itapocú, representado esquematicamente sobre o mosaico das fotografias aéreas de 1995.

De forma a obter informações quantitativas sobre o comportamento morfológico do canal e de suas margens, foram definidos 10 perfis paralelos à linha de costa que cortam o canal e as suas margens (Fig. 3). Esses dez perfis foram extraídos a partir da malha de pontos interpolados para cada um dos levantamentos morfológicos, iniciando no norte, sendo o perfil 1 do lado do oceano e o perfil 10 do lado da laguna. Para a análise comparativa entre os perfis, a partir de uma análise inicial, foram selecionados os três perfis que melhor representam a variação morfológica do sistema.

\section{Dados de ondas}

Os dados de onda foram obtidos de Araújo et al. (2003). Esses autores apresentam a análise estatística de um ano de dados obtidos com um ondógrafo fundeado a $35 \mathrm{~km}$ da Ilha de Santa Catarina a aproximadamente $80 \mathrm{~m}$ de profundidade (dados coletados pelo LAHIMAR/UFSC e analisados e publicados por Araújo et al., 2003). Esses dados foram coletados de dezembro de 2001 a janeiro de 2003, com observações horárias do estado do mar com um erro menor do que 15\%. Uma das limitações na utilização desses dados para os experimentos numéricos é que eles não correspondem ao período dos levantamentos morfológico. No entanto, como não existem outros levantamentos de dados de ondas disponíveis para a região assumimos que apesar de compreenderem apenas um ano, estes dados fornecem uma visão geral do comportamento sazonal das ondas para a região.

Para suprir a ausência de dados de ondas medidos na região de interesse para o período do monitoramento morfológico, foram utilizados dados extraídos do modelo global de geração de ondas WAVEWATCH III (Tolman, 1997, 1999). 0 modelo é operacionalizado pela NOAA com dados de entrada oriundos do NCEP (National Centers for Environmental Prediction). Essa combinação de entrada e modelo de ondas é chamada de NOAA WAVEWATCH III, ou NWW3. Os produtos oriundos desses modelos estão disponíveis através de séries históricas na página (http://polar.ncep.noaa.gov/waves/index2.shtml).

Para obter o padrão de refração de ondas na região a partir dos dados de ondas de Araújo et al. (2003) e do modelo de ondas NWW3, um modelo numérico de refração de ondas foi aplicado. 0 modelo numérico implementado foi o MIKE 21 desenvolvido pelo DHI Water \& Environment com seu módulo de propagação e transformação de ondas (MIKE 21 SW - Spectral Wind-Wave). 0 modelo leva em consideração 0 efeito de refração e empinamento devido à variação da profundidade, geração de ondas locais e dissipação de energia devido à fricção com o fundo e quebra da onda (DHI, 2003). 0 efeito de difração de onda não é incluído na formulação do modelo. 0 modelo MIKE 21 SW é estacionário, deriva de equações básicas da equação de conservação de massa para densidade da ação espectral das ondas proposta por Holthuijsen et al. (1989).

Uma vez que não existem dados de ondas medidos na região que possibilitassem a validação do modelo numérico, assumimos que os processos de propagação, empinamento e refração de ondas são bem reproduzidos em sua formulação. Apesar dessa limitação, é possível afirmar que os modelos numéricos atuais reproduzem com boa qualidade os processos de transformação de ondas em águas rasas. Aplicação similar também foi conduzida por Siegle \& Asp (2007) para o litoral sul de SC.

A condição de contorno externa do modelo é definida com a altura significativa das ondas (Hs), período de onda (T), direção 
de incidência das ondas (dir) e o seu desvio padrão (DSD). As condições de contorno para os limites laterais do modelo (norte e sul) foram assumidas simétricas. A fricção com o fundo foi especificada com o parâmetro de rugosidade de Nikuradse $(0,002 \mathrm{~m})$, e a elevação da superfície do mar foi considerada constante.

Para a obtenção dos padrões de propagação de ondas foram realizadas 54 simulações abrangendo os quadrantes Nordeste, Leste, Sudeste e Sul para os dados de ondas obtidos a partir da análise de Araújo et al. (2003) e 13 simulações referentes aos dados de ondas mensais de julho de 2004 a julho de 2005 obtidos do modelo NWW3.

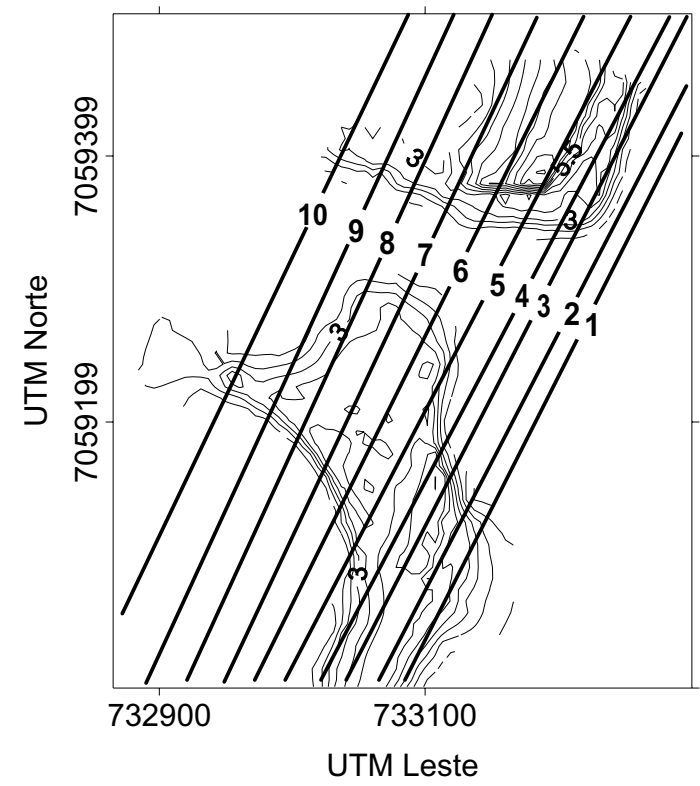

Figura 3 - Morfologia do dia 02 de dezembro de 2004 com a representação dos 10 perfis definidos para a extração das informações quantitativas dos levantamentos.

\section{Estimativa da deriva litorânea potencial}

A estimativa potencial da deriva litorânea foi realizada segundo método de Longuet-Higgins (1970) e Komar (1998), que considera que a energia de onda é diretamente proporcional ao quadrado da altura, e que a intensidade da deriva é proporcional ao ângulo no qual a frente de onda se aproxima à costa; como dado por:

$$
y=\sin \alpha \cdot \cos \alpha
$$

onde $y$ é 0 fator intensidade para deriva potencial e $\alpha$ é 0 ângulo de incidência da onda. Incluindo a altura de onda próximo a costa, a deriva litorânea potencial adimensional $(x)$ foi obtida por unidade de área.

$$
x=y \cdot H^{2}
$$

Para a estimativa da deriva litorânea potencial, a região foi dividida em 10 segmentos com orientação similar em relação ao norte. Assim, com a extração dos ângulos de incidência das ondas refratadas do modelo numérico em pontos definidos em frente a cada segmento, foi obtido o ângulo de incidência das ondas em relação à linha de costa. Tanto os ângulos de incidência como as alturas das ondas refratadas foram extraídas para cada segmento na isóbata aproximada de $4 \mathrm{~m}$. Posteriormente, os valores obtidos para a intensidade da deriva a partir da aplicação das Equações 1 e 2 foram multiplicados pela percentagem da frequência anual de ocorrência para cada evento de onda.

\section{Vazão fluvial}

Os dados de vazão utilizados na presente análise foram obtidos através da Agência Nacional das Águas (ANA) e da Empresa de Pesquisa Agropecuária e Extensão Rural de Santa Catarina (Epagri)/Centro de Informações de Recursos Ambientais e de Hidrometeorologia de Santa Catarina (CIRAM). Para a caracterização do regime fluviométrico foram utilizados os dados históricos de maio de 1977 até outubro de 2000. Para 0 acompanhamento da vazão ao longo do período de monitoramento morfológico, em função da disponibilidade, foram utilizados os dados de junho de 2004 a janeiro de 2005 (referentes à bacia do rio Itapocú) e de fevereiro de 2005 a junho de 2005 (dados referentes à estação de Indaial, na bacia do rio Itajaí-Açú). A correção para a equivalência entre as bacias hidrográficas foi realizada através da proporção de suas áreas.

\section{RESULTADOS}

\section{Morfologia e migração da desembocadura}

Qualitativamente, a evolução morfológica dos pontais arenosos é bem visualizada através de diagramas tridimensionais representando os cinco levantamentos (Fig. 4). Nessa representação, além da migração do canal, é possível observar feições morfológicas que compõem o sistema, como os bancos arenosos que fazem parte do delta de maré vazante. Esse banco, resultante da deposição de sedimentos junto ao pontal sul, é mais evidente no levantamento do dia 05 de agosto de 2004, aparecendo novamente no levantamento do dia 03 de junho de 2005. A migração no centro do canal diminui após o levantamento de dezembro de 2004, iniciando a migração para o norte na sua porção interior. No dia 20 de abril de 2005 o canal estava mais estreito no lado da laguna, porém no lado do oceano a sua largura aumentou ao longo do monitoramento. Ao longo dos três primeiros levantamentos, o pontal norte se apresenta mais exposto a ação das ondas devido à inclinação do canal, favorecendo o processo ero- 

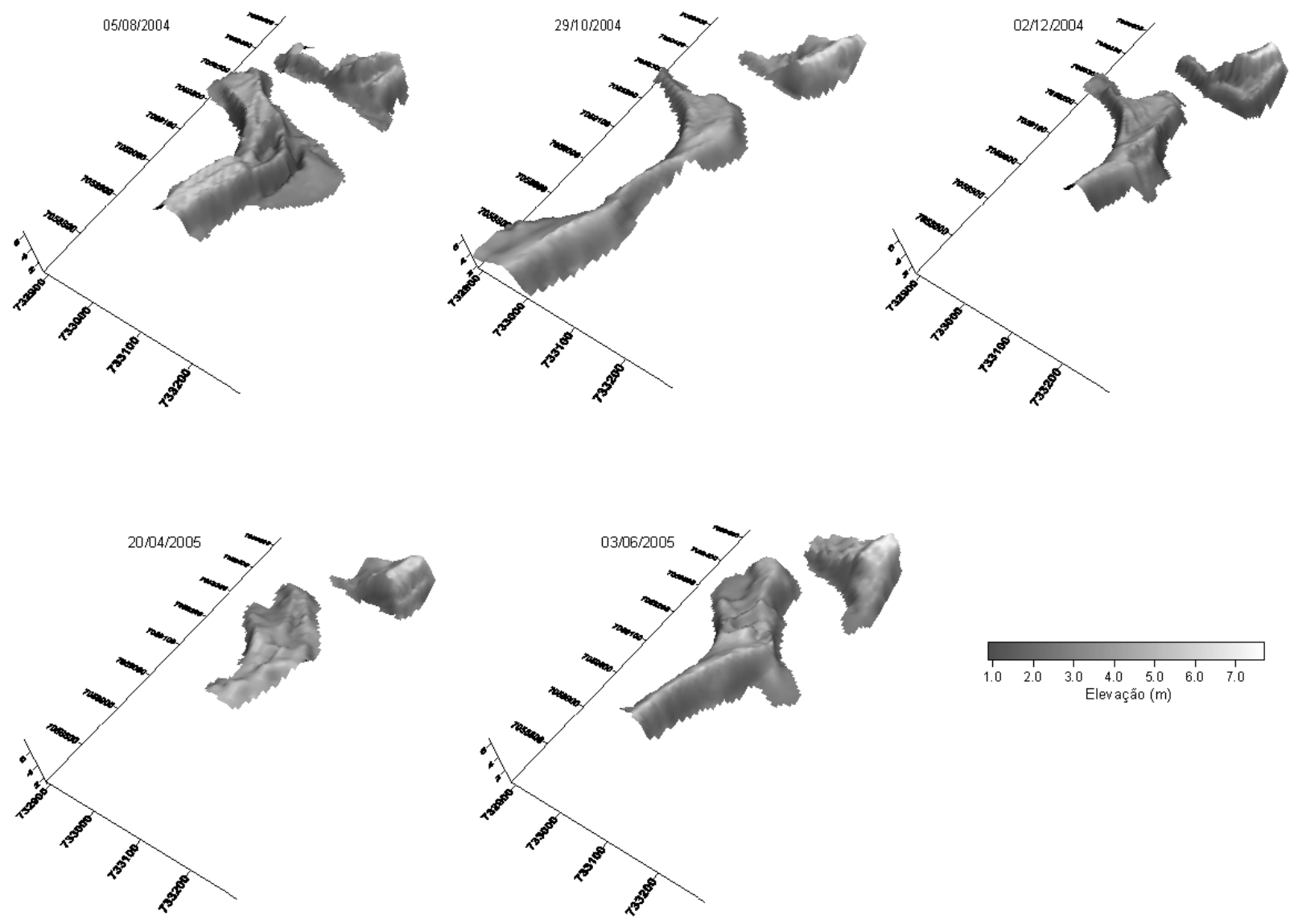

Figura 4 - Diagramas tridimensionais dos pontais arenosos que definem o canal.

sivo ao qual estava submetido. Entre os levantamentos é visível a variação do ângulo do canal em relação ao norte, alterando a sua exposição à ação das ondas. Observações qualitativas preliminares baseadas nos levantamentos morfológicos podem ser encontradas também em Piérri \& Siegle (2005) e Piérri (2005).

Informações quantitativas são obtidas a partir da comparação entre os levantamentos com base em sua representação gráfica. A representação das malhas topográficas interpoladas é disposta conforme os períodos de coleta: 05/08/2004 - inverno; 29/10/2004 - primavera; 02/12/2004 - verão; 20/04/2005 - outono e 03/06/2005 - final do outono. Para melhor visualização da posição dos pontais arenosos norte e sul foi definida uma cota comum para todos os levantamentos (cota de $3 \mathrm{~m}$ ). Essa cota não representa necessariamente a linha de costa, mas permite a comparação visual entre os levantamentos através do mesmo referencial (Fig. 5). Nessa análise comparativa observa-se a grande dinâmica do canal e pontais arenosos entre os levantamentos sequenciais. De forma geral, observa-se a acentuada erosão do pontal norte e deposição no pontal sul, levando 0 canal a mi- grar em direção ao norte e mudar a sua orientação no período final do monitoramento. A Tabela 1 apresenta valores da taxa de erosão/acresção para os pontais norte e sul. Através da análise da posição das margens do canal na sua porção central (perfil 6 da Fig. 3), observa-se a sua migração e mudanças em sua largura, que apresentou um aumento de aproximadamente $20 \mathrm{~m}$ ao longo do período monitorado (Fig. 6).

Tabela 1 - Taxa de migração diária para o pontal arenoso norte e sul. (+) indica acresção e (-) indica erosão.

\begin{tabular}{|c|c|c|c|}
\hline Período & Dias & $\begin{array}{c}\text { Pontal Norte } \\
\text { Taxa }\left(\mathrm{m} . d i a^{-1}\right)\end{array}$ & $\begin{array}{c}\text { Pontal Sul } \\
\text { Taxa }\left(\mathrm{m} . d i a^{-1}\right)\end{array}$ \\
\hline 05/08/04-29/10/04 & 85 & $-0,561$ & $+0,447$ \\
\hline $29 / 10 / 04-02 / 12 / 04$ & 34 & $+0,366$ & $+0,017$ \\
\hline $02 / 12 / 04-20 / 04 / 05$ & 138 & $-0,510$ & $+0,366$ \\
\hline $20 / 04 / 05-03 / 06 / 05$ & 44 & $+0,140$ & $+0,253$ \\
\hline
\end{tabular}

Refração de ondas e deriva litorânea potencial

Através da utilização dos dados de ondas refratadas para a região de interesse foram estimados os valores da deriva litorânea po- 

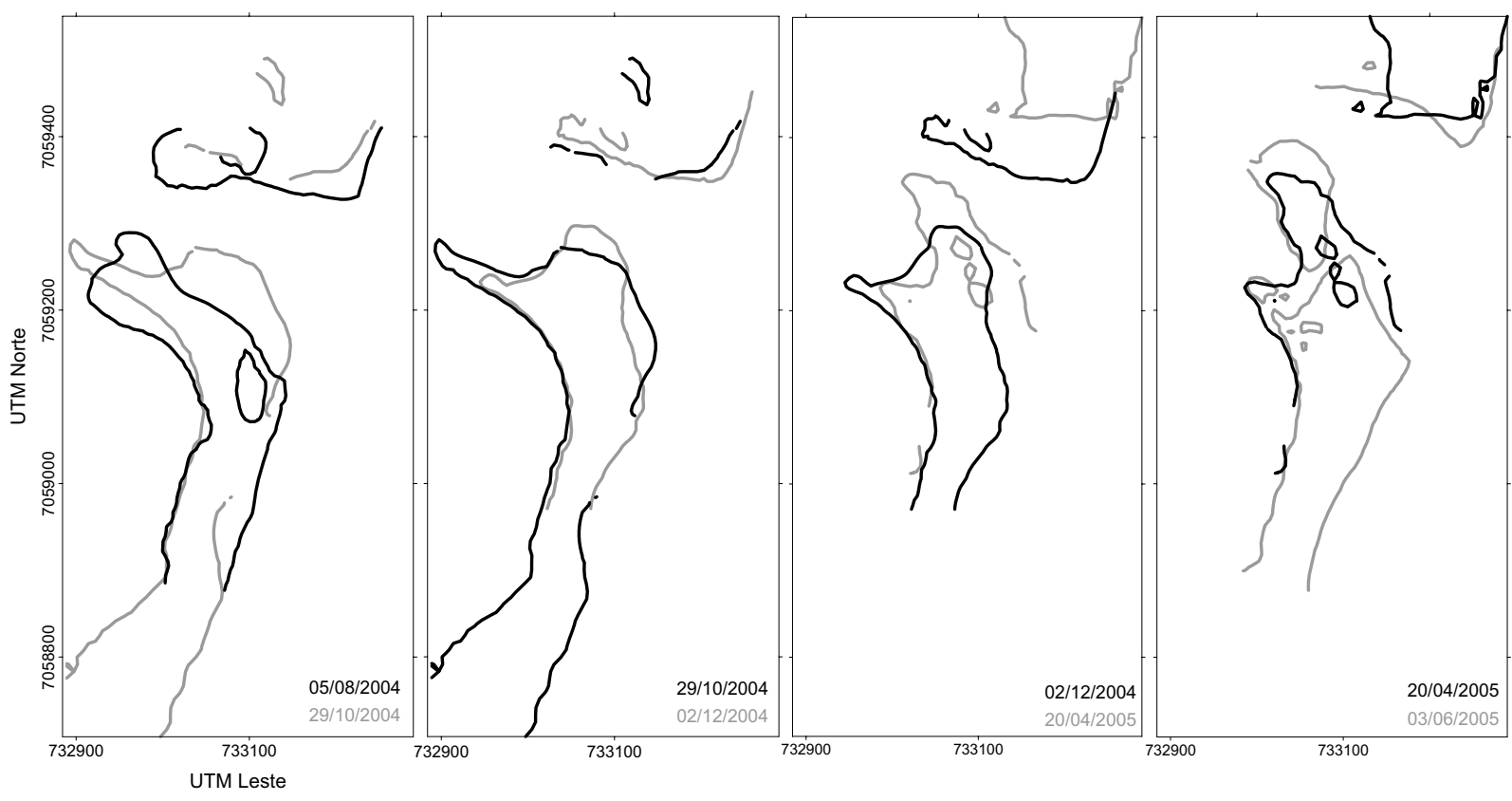

Figura 5 - Comparação da linha de costa entre os levantamentos, na cota de $3 \mathrm{~m}$. Comparação a cada dois levantamentos sequenciais.

tencial. Este é o primeiro estudo quantitativo sobre 0 padrão de deriva para a região, apresentando informações interessantes sobre a deriva ao longo da barreira arenosa que compõem a região da laguna/desembocadura do rio ltapocú. A deriva potencial anual obtida através da condição de contorno definida com base nos dados de Araújo et al. (2003) mostrou a predominância do sentido norte-sul, enquanto que a variação sazonal do clima de ondas mostrou diferenças nos sentidos da deriva litorânea potencial. Nos meses de primavera e verão, quando ocorre predominância das ondas de leste, 0 sentido da deriva seguiu o padrão da deriva anual, norte-sul, com pequenas regiões tendo 0 sentido sul-norte. No outono ocorre a inversão no sentido da deriva, passando a predominar o sentido sul-norte. As regiões dos pontais arenosos apresentaram 0 sentido predominante da deriva nessa estação, apenas alguns segmentos tiveram 0 sentido oposto, como o segmento I, bem ao norte, e os segmentos IX e $X$, ao sul. No inverno predomina novamente a deriva com sentido norte-sul, existindo no entanto uma inversão na deriva na porção sul da barreira arenosa, (Fig. 7). Analisando a deriva para cada estação obteve-se para a primavera deriva potencial mais intensa, seguida pelo verão, outono e inverno.

Os dados de deriva litorânea obtidos a partir dos dados climatológicos de ondas do modelo NWW3, correspondentes ao período do monitoramento, mostraram diferenças nos sentidos de deriva quando comparados aos obtidos a partir dos dados de Araújo et al. (2003). Para a obtenção da deriva por inter- valos entre os levantamentos foram considerados dois levantamentos sequenciais. A deriva litorânea apresentou direção dominante para 0 norte, com variações ocorrendo em função da orientação da linha de costa e a variabilidade sazonal do clima de ondas (Fig. 8).

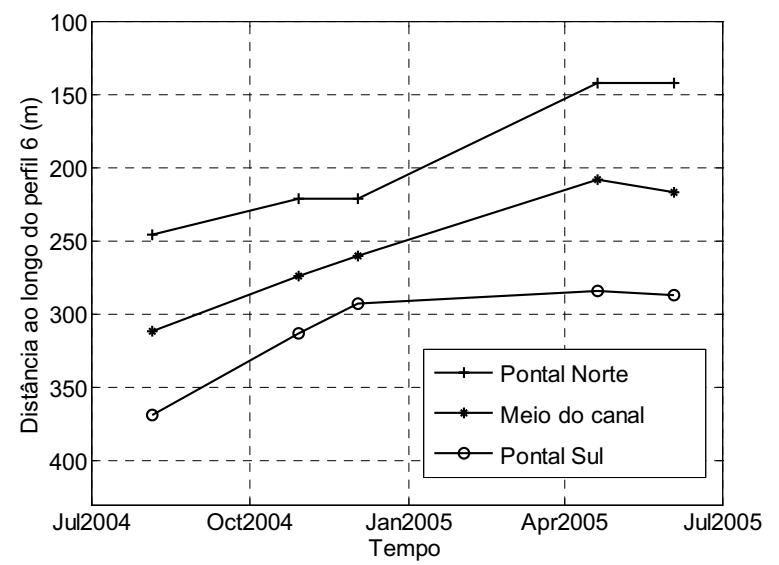

Figura 6 - Migração do canal durante os cinco levantamentos para o perfil 6.

\section{DISCUSSÃO}

A tendência geral da desembocadura foi uma acentuada migração em direção ao norte ao longo da barreira arenosa, no entanto, analisando os padrões de erosão e acresção dos pontais arenosos, 0 período monitorado apresentou taxas de migração cujas magnitudes oscilaram entre os levantamentos. Apesar de historicamente existirem evidências de que 0 canal já migrou para 0 sul em de- 

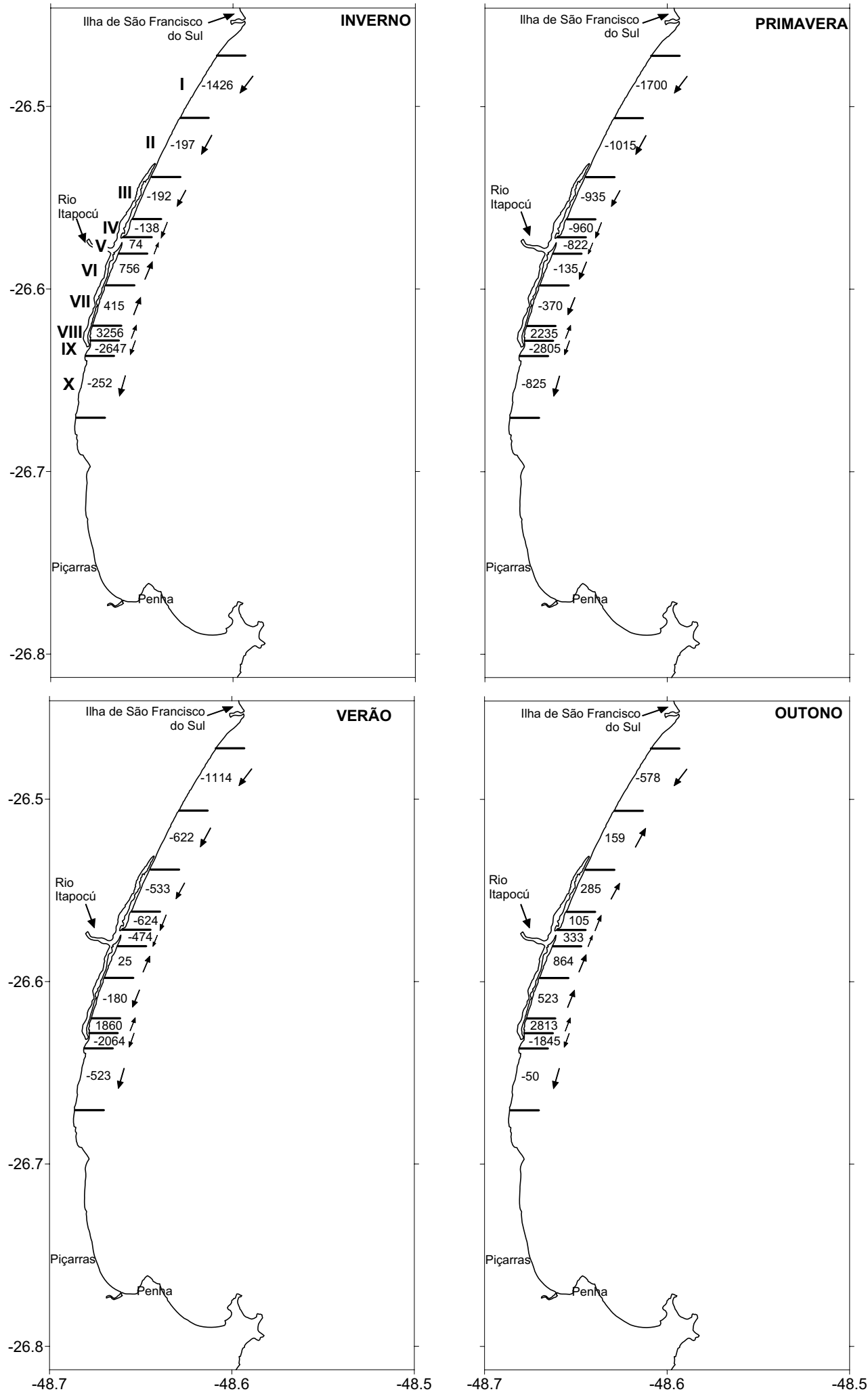

Figura 7 - Deriva potencial para estações do ano para cada segmento. Condição de contorno definida a partir dos dados de Araújo et al. (2003). Na figura referente ao inverno estão indicados os setores definidos para a análise. 

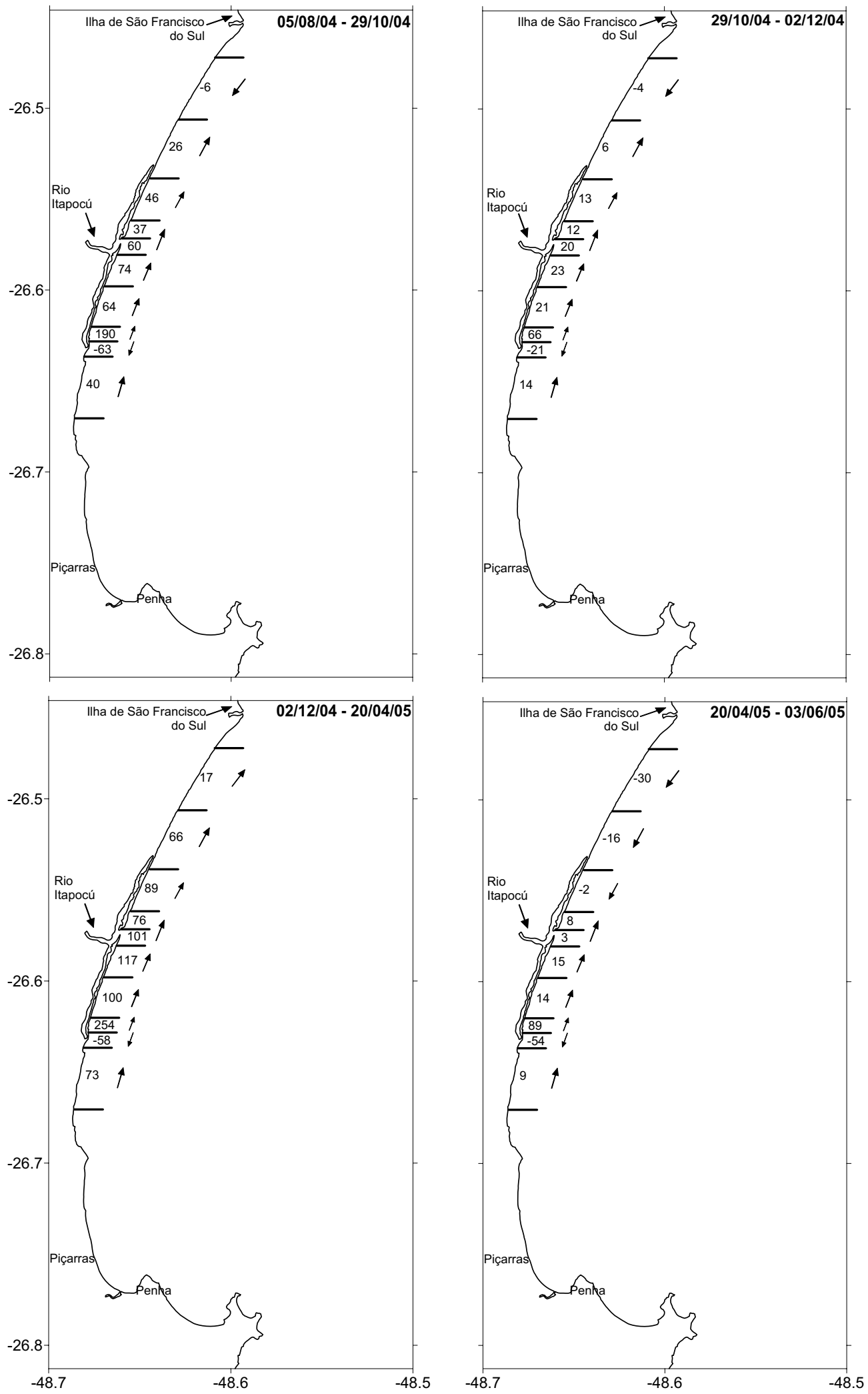

Figura 8 - Deriva potencial para os intervalos entre os levantamentos morfológicos sequenciais. Condições de contorno extraídas do modelo NWW3. 
terminados períodos, a migração em sentido ao norte parece ser mais frequente e notável. A Tabela 2 apresenta um resumo de todas as variáveis físicas obtidas ao longo do período de monitoramento, permitindo a comparação entre os levantamentos.

Correlacionando o período de migração mais intensa do canal com a deriva litorânea potencial, observa-se que para os dados obtidos utilizando como condição de contorno as ondas observadas ao longo de 2002 (Araújo et al., 2003), que demonstraram sentido de migração para o sul, não correspondem ao sentido de migração do canal. Assim, não é possível estabelecer uma relação entre estes parâmetros, demonstrando a existência de variabilidade interanual no clima de ondas para a região. Os dados de deriva litorânea obtidos a partir do modelo de ondas global NWW3 para o período do monitoramento, apresentaram sentido sul-norte, concordando com o sentido de migração da desembocadura. Esses resultados são mais condizentes com os dados morfológicos obtidos, indicando a influência da deriva na migração do canal durante 0 ano monitorado.

0 padrão geral da deriva litorânea potencial para os cinco segmentos adjacentes a desembocadura mostra que, no período de outubro de 2004 a abril de 2005, a deriva potencial é continuamente para 0 norte. Do total de $100 \mathrm{~m}$ que 0 canal migrou para 0 norte, nesses meses ocorreu a migração de aproximadamente $75 \mathrm{~m}$. Entre os dois últimos levantamentos, o centro do canal não migrou, apresentando apenas uma rotação de seu eixo principal para 0 sul. Nesse último período, entre abril e junho de 2005, a deriva litorânea apresenta uma diminuição em sua magnitude até a inversão em junho de 2005.

A orientação do canal, que segundo Aubrey \& Speer (1984) pode ser um dos fatores controladores na migração de canais, inclusive com sentido contrário ao da deriva litorânea dominante, não parece ter afetado o padrão observado para 0 canal do rio Itapocú no período monitorado. Segundo FitzGerald (1982), a orientação do canal da desembocadura é uma função complexa do balanço entre a taxa de sedimento transportado pela deriva e prisma de maré, combinando com a migração da desembocadura. No entanto, a interação desses fatores é difícil de ser provada (Morris et al., 2001). A mudança na inclinação do eixo do canal do rio Itapocú apresentou pequenas variações não sendo possível estabelecer uma relação com as taxas de migração. Durante a maior parte do período, de agosto de 2004 a abril de 2005, o canal ficou voltado para o norte, resultando em uma maior exposição da margem norte à ação das ondas e a um eventual efeito de meandramento em função dos fluxos no canal. Essa orientação seria favorável a uma maior taxa de migração para norte em função da maior resuspensão e transporte de sedimentos ao longo da mar- gem norte do canal. No último período monitorado, quando existe uma inversão na orientação do canal para sul, é o período em que não ocorreu migração do canal. Esse fato pode estar relacionado à menor exposição da margem norte do canal à ação das ondas. No entanto, como houve também uma diminuição na intensidade da deriva litorânea nesse período, é mais provável que a deriva seja o principal fator controlador da migração do canal.

A descarga fluvial e o prisma de maré para o sistema ao longo dos períodos monitorados não apresentaram relação direta com o padrão de migração observado. No entanto, parece existir uma relação da largura do canal com esses fatores. Considerando que existe a relação direta entre o volume do prisma de maré e da descarga fluvial com a área da seção mínima do canal (e.g. relações de estabilidade formuladas por O'Brien, 1971), as informações analisadas mostram que em agosto de 20040 canal apresentou a largura mínima, aumentando nos meses seguintes. Considerando a descarga para quinzena antecedente a cada levantamento não foi possível verificar nenhum padrão, porém analisando a variação sazonal da descarga é possível relacionar essas variáveis. Durante a primavera ocorreu o maior valor de descarga e a largura nesse período foi máxima, no inverno, estação de seca, a largura do canal foi mínima. Essa relação mostra que a resposta do canal para variações na descarga fluvial é de médio termo (escala sazonal), não dependendo de oscilações de alta frequência no padrão da descarga. Na presente análise não é possível estabelecer as variações da morfologia do canal em função das variações do prisma de maré (em função da fase da maré), mas a resposta do canal deve ser um comportamento de equilíbrio médio em função do prisma (Jarret, 1976). Assim, apesar da maior largura do canal observada ser coincidente com 0 valor máximo estimado de prisma de maré (outubro de 2004), foi também nesse período em que ocorreu a maior vazão fluvial. Como no restante do período não existe um padrão de resposta da largura do canal com o prisma de maré no período do levantamento, as larguras parecem estar sendo controladas pelo prisma de maré como situação de equilíbrio, com variações sazonais em função de variações na descarga fluvial.

A comparação entre os dados de deriva litorânea potencial obtidos com os dados de Araújo et al. (2003) com aqueles obtidos a partir da extração de dados do modelo NWW3, mostra que deve existir uma variação interanual no clima de ondas na região. Enquanto os dados de ondas medidos para 0 ano de 2002 (Araújo et al., 2003) indicam transporte dominante para sul, com inversões ao longo do ano, os dados extraídos do modelo NWW3 para o período estudado resultam em comportamento diferente na costa, com dominância de deriva para norte. Essa possível 
Tabela 2 - Resumo das condições físicas ao longo do período de monitoramento morfológico.

\begin{tabular}{|c|c|c|c|c|c|c|c|c|c|c|}
\hline & $\begin{array}{c}\text { Vazão } \\
1 \\
\left(\mathrm{~m}^{3} \cdot \mathrm{s}^{-1}\right)\end{array}$ & $\begin{array}{c}\text { Vazão } \\
2 \\
\left(\mathrm{~m}^{3} \cdot \mathrm{s}^{-1}\right)\end{array}$ & $\begin{array}{c}\text { Taxa de } \\
\text { migração } \\
\left(\mathrm{m}_{\mathrm{dia}}{ }^{-1}\right)\end{array}$ & $\begin{array}{c}\text { Taxa de } \\
\text { migração } \\
\text { do canal } \\
\left(\text { m.dia }^{-1}\right) \\
\text { P3 ao P9 }\end{array}$ & $\begin{array}{l}\text { Largura } \\
\text { do } \\
\text { canal } \\
\text { (m) }\end{array}$ & $\begin{array}{l}\text { Ângulo } \\
\text { do } \\
\text { canal* }^{*} \\
\left({ }^{\circ}\right)\end{array}$ & $\begin{array}{c}\text { Deriva } \\
\text { litorânea } \\
\text { (Araújo et } \\
\text { al., 2003) }\end{array}$ & $\begin{array}{c}\text { Deriva } \\
\text { litorânea } \\
\text { (NWW3) }\end{array}$ & $\begin{array}{l}\text { Maré } \\
(\mathrm{m})\end{array}$ & $\begin{array}{c}\text { Prisma } \\
\text { de maré } \\
\left(\mathrm{m}^{3}\right)\end{array}$ \\
\hline $\begin{array}{c}\text { Inverno } \\
\text { 05/08/04 }\end{array}$ & & $\begin{array}{c}85,79 \\
(21 / 07)\end{array}$ & & & $\begin{array}{c}37,597 \\
(\mathrm{P} 10)\end{array}$ & +9 & $915 \mathrm{~N}$ & & $\begin{array}{c}1,1 \\
\text { (início da } \\
\text { quadratura) }\end{array}$ & 3573900 \\
\hline $\begin{array}{c}\text { Primavera } \\
29 / 10 / 04\end{array}$ & 29,28 & $\begin{array}{c}20,80 \\
(14 / 10)\end{array}$ & $\begin{array}{l}P N-0,561 \\
P S+0,447\end{array}$ & 0,48 & $\begin{array}{c}92,563 \\
(\mathrm{P} 6)\end{array}$ & +12 & 3222 S & $283,0 \mathrm{~N}$ & $\begin{array}{c}1,4 \\
\text { (sizígia) }\end{array}$ & 4548600 \\
\hline $\begin{array}{c}\text { Verão } \\
\text { 02/12/04 }\end{array}$ & 12,54 & $\begin{array}{c}9,67 \\
(17 / 11)\end{array}$ & $\begin{array}{l}P N+0,366 \\
P S+0,017\end{array}$ & $-0,14$ & $\begin{array}{c}55,209 \\
(P 7)\end{array}$ & +7 & $1786 \mathrm{~S}$ & $91,8 \mathrm{~N}$ & $\begin{array}{c}0,9 \\
\text { (início da } \\
\text { quadratura) }\end{array}$ & 2924100 \\
\hline $\begin{array}{c}\text { Outono } \\
\text { 20/04/05 }\end{array}$ & 20,26 & $\begin{array}{c}52,06 \\
(05 / 04)\end{array}$ & $\begin{array}{l}P N-0,510 \\
P S+0,366\end{array}$ & $-0,47$ & $\begin{array}{l}61,760 \\
(P 9)^{\star}\end{array}$ & +5 & $2110 \mathrm{~N}$ & $486,7 \mathrm{~N}$ & $\begin{array}{c}1,2 \\
\text { (início da } \\
\text { sizígia) }\end{array}$ & 3898800 \\
\hline $\begin{array}{c}\text { Final } \\
\text { Outono } \\
\text { 03/06/05 }\end{array}$ & 15,14 & $\begin{array}{l}143,56 \\
(19 / 05)\end{array}$ & $\begin{array}{l}P N-0,140 \\
P S+0,253\end{array}$ & 0,00 & $\begin{array}{c}50,562 \\
(P 9)\end{array}$ & -3 & & $22,8 \mathrm{~N}$ & $\begin{array}{c}1,0 \\
\text { (início da } \\
\text { sizígia) }\end{array}$ & 3249000 \\
\hline
\end{tabular}

Inverno - 21/06 até 23/09. Primavera - 23/09 até 21/12. Verão - 21/12 até 21/03. Outono - 21/03 até 21/06. Vazão $1-$ vazão média de cada estação. Vazão $2-$ Vazão média da quinzena que antecedeu cada levantamento. PN - Pontal Norte. PS - Pontal Sul. Largura do canal é referente à menor seção transversal obtida entre oS pontais arenosos norte e sul. 0 perfil referente à seção está descrito abaixo do valor de largura. * ângulo do canal em relação à normal à linha de costa; (+) para norte, (-) para sul. Deriva litorânea para Araújo et al. (2003) é referente aos segmentos III ao VII, localizados em frente aos pontais. Deriva litorânea para WAVEWATCH é referente ao intervalo de dois levantamentos sequenciais. Os valores são referentes aos segmentos III ao VII localizados em frente aos pontais.

variação interanual pode auxiliar na explicação da migração da desembocadura para o sul em determinados períodos.

\section{CONCLUSÕES}

Através da abordagem de estudo adotada, unindo informações quantitativas sobre a evolução morfológica da desembocadura com informações sobre as forçantes físicas do ambiente, é possível chegar a conclusões relevantes e inéditas sobre 0 comportamento do ambiente estudado.

\section{Evolução morfológica}

- A migração do canal apresentou oscilações em sua taxa de migração diária ao longo do período monitorado, relacionadas às condições forçantes de sua dinâmica;

- Feições geomorfológicas presentes no pontal sul indicam 0 domínio da deriva litorânea de sul para norte; 0 canal atuando como molhe hidráulico impede que parte do sedimento transportado atravesse 0 canal levando à deposição na forma de bancos em sua porção sul;

- 0 eixo do canal principal da desembocadura apresentou rotação em relação à linha de costa, passando de um canal voltado para o norte para um canal levemente voltado para o sul ao final do período de monitoramento;

- A rotação do canal pode levar à maior ou menor exposição de suas margens à ação das ondas, aumentando ou diminuindo a sua taxa de migração.

\section{Deriva litorânea}

- 0 padrão de deriva litorânea obtido a partir da aplicação do modelo numérico de refração de ondas sugerem a existência de diferenças interanuais no clima de ondas na região;

- Experimentos numéricos baseados nos dados medidos em 2002 e analisados por Araújo et al. (2003) indicam dominância de deriva litorânea potencial para sul, enquanto os experimentos baseados nos dados extraídos do modelo de previsão global de ondas WAVEWATCH III para 0 período do monitoramento morfológico (agosto de 2004 a junho de 2005) mostram dominância da deriva litorânea potencial para norte; 
- Existem inversões sazonais na direção e magnitude da deriva litorânea potencial na região, dependendo da incidência sazonal das ondas;

- As variações na deriva litorânea potencial na região, tanto sazonalmente como interanualmente, podem auxiliar na explicação da migração da desembocadura para o sul em determinados períodos;

- A migração da desembocadura ao longo do período monitorado está diretamente relacionada com o padrão de deriva litorânea potencial estimado;

- Assim, entre as variáveis analisadas, podemos afirmar que a deriva litorânea controlou a migração do canal ao longo do período de estudo.

\section{Descarga fluvial}

- A descarga fluvial, na escala e no período analisado, não apresenta relações com a migração do canal;

- A largura do canal parece ser influenciada pela descarga fluvial na escala sazonal, mas não são verificadas respostas em curto período no comportamento morfológico da desembocadura;

- Essa relação mostra que a resposta do canal para variações na descarga fluvial é de médio termo (escala sazonal), não dependendo de oscilações de alta frequência no padrão da descarga. Na presente análise não é possível estabelecer as variações da morfologia do canal em função das variações do prisma de maré (em função da fase da maré), mas a resposta do canal deve ser um comportamento de equilíbrio médio em função do prisma;

- A largura do canal parece ser controlada pelo prisma de maré como situação de equilíbrio, com variações sazonais em função de variações na descarga fluvial.

\section{AGRADECIMENTOS}

Os dados utilizados no presente trabalho foram coletados como parte do Projeto CANAIS (financiado pela FAPESC) e desenvolvido em conjunto com colegas do CTTMar/UNIVALI. Os autores agradecem a equipe do Projeto CANAIS pelo auxílio nos levantamentos de campo. G.F.C. agradece a bolsa de mestrado (CAPES) recebida para o desenvolvimento do trabalho. E.S. é bolsista de produtividade em pesquisa CNPq (305805/2009-6).

\section{REFERÊNCIAS}

ABREU CF de, SIEGLE E, TRUCCOLO EC \& SCHETTINI CAF. 2010. Hydrodynamics of the Itapocu river and the Barra Velha lagoon estuarine system, SC, Brazil. Revista Brasileira de Geofísica, 28(3): 321-329.

ARAÚJO CES, FRANCO D, MELO E \& PIMENTA F. 2003. Wave Regime Characteristics of the Southern Brazilian Coast. In: Proceedings of the Sixty International Conference on Coastal and Port Engineering in Developing Countries, COPEDEC VI, Sri Lanka. Ed. Colombo, 2003. Paper No. 097. CD-ROM.

AUBREY DG \& SPEER PE. 1984. Updrift Migration of Tidal Inlets. J. Geol., 92: 531-545.

DE VRIEND HJ. 1996. Mathematical modeling of meso-tidal barrier island coasts. Part I: empirical and semi-empirical models. In: LIU PL-F (Ed.). Advances in Coastal and Ocean Engineering, Vol. 2, World Scientific Publishing. pp. 115-149.

DHI - Danish Hydraulic Institute. 2003. MIKE 21 Nearshore Spectra Wind-Wave Module. User Guide and Reference Manual. 221 p.

FENSTER MS \& DOLAN R. 1996. Assessing the impact of tidal inlets on adjacent barrier island shorelines. J. Coast. Res., 12: 294-310.

FITZGERALD DM. 1982. Sediment bypassing at mixed energy tidal inlets. In: Proceedings of $18^{\text {th }}$ Coastal Engineering Conference, ASCE, Cape Town, South Africa. p. 14-19.

FITZGERALD DM. 1988. Shoreline erosional-depositional processes associated with tidal inlets. In: MEHTA AJ (Ed.). Estuarine Cohesive Sediment Dynamics. Lecture Notes on Coastal Estuarine Studies. pp. 186-225.

FITZGERALD DM. 1996. Geomorphic variability and morphologic and sedimentologic controls on tidal inlets. J. Coast. Res., SI 23: 47-71.

GAPLAN. 1986. Atlas de Santa Catarina. Gabinete de Planejamento e Coordenação Geral. Subchefia de Estatística, Geografia e Informática. $173 \mathrm{p}$.

HOLTHUIJSEN LH, BOOIJ N \& HERBERS THC. 1989. A prediction model for stationary, short-crested waves in shallow water with ambient currents. Coast. Eng., 13: 23-54.

JARRETT JT. 1976. Tidal prism-inlet area relationships. GITI Report No. 3, U.S. Army Corps of Engineers, Waterways Experiment Station, Vicksburg, Mississippi, 54 p.

KANA TW, HAYTER EJ \& WORK PA. 1999. Mesoscale sediment transport at Southeastern US tidal inlets: Conceptual model applicable to mixed energy setting. J. Coast. Res., 15: 303-314.

KOMAR PD. 1996. Tidal-Inlet Processes and Morphology Related to the Transport of Sediments. J. Coast. Res., SI 23: 23-45.

KOMAR PD. 1998. Beach processes and sedimentation. $2^{\text {nd }}$ ed. Prentice Hall. $544 p$. 
LONGUET-HIGGINS MS. 1970. Longshore currents generated by obliquely incident sea waves. J. Geophys. Res., 75(33): 6778-6789.

MEHTA AJ. 1996. A Perspective on Process Related Research Needs for Sandy Inlets. J. Coast. Res., SI 23: 3-21.

MIRANDA EE de (Coord.). 2005. Brasil em Relevo. Campinas: Embrapa Monitoramento por Satélite. Disponível em:

$<$ http://www.relevobr.cnpm.embrapa.br> . Acesso em: 27 ago. 2009.

MONTEIRO CAF. 1968. Clima. In: Geografia Regional do Brasil, Região Sul. Vol. IV, Tomo I, Cap. III. Rio de Janeiro, Biblioteca Geográfica Brasileira. IBGE, p. 114-166.

MORRIS BD, DAVIDSON MA \& HUNTLEY DA. 2001. Measurements of the Response of a Coastal Inlet using Video Monitoring Techniques. Mar. Geol., 175: 251-272.

NIMER E. 1989. Climatologia do Brasil. Recursos Naturais e Meio Ambiente 4. Rio de Janeiro, IBGE, $421 \mathrm{p}$.

NOBRE CA, CAVALCANTI MAG, NOBRE P, KAYANO MT, RAO VB, BONATTI JP, SATYAMURTI P, UVO CB \& COHEN JC. 1986. Aspectos da climatologia dinâmica do Brasil. Climanálise. Número especial. 124 p.

O'BRIEN MP. 1971. Notes on tidal inlets on sandy shores. Hydraulic Engineering Laboratory Report No. HEL-24-5, University of California, Berkeley, May. $56 \mathrm{p}$.

PIANCA C, MAZZINI PL \& SIEGLE E. 2010. Brazilian offshore wave climate based on NWW3 reanalysis. Braz. J. Oceanogr., 58(1): 53-70.

PIÉRRI GCS. 2005. Variabilidade da desembocadura do rio Itapocú: análise da evolução morfológica em escalas de médio e curto-termo. Curso de Graduação em Oceanografia. Universidade do Vale do Itajaí. Trabalho de Conclusão de Curso. 83 p.

PIÉRRI GCS \& SIEGLE E. 2005. Variabilidade da desembocadura do rio Itapocú/SC - Brasil: análise da evolução morfológica em escalas de curto-termo. In: II Congresso Brasileiro de Oceanografia, Vitória, CDROM.

SCHETTINI CAF \& CARVALHO JLB. 1998. Hidrodinâmica e Distribuição de Sedimentos em Suspensão dos Estuários dos Rios Itapocú, Tijucas e Camboriú. Notas Técnicas da Facimar, 2: 141-153.

SCHETTINI CAF \& KLEIN AHF. 1997. Processos Costeiros e Dinâmica Estuarina: um Modelo para o Estuário do Rio Itapocú, Santa Catarina. In: VI Congresso da Associação Brasileira de Estudos do Quaternário, Curitiba, p. 127-131.

SIEGLE E \& ASP NE. 2007. Wave Refraction and Longshore Transport Patterns along the Southern Santa Catarina Coast. Braz. J. Oceanogr. 55(2): 109-120.

SIEGLE E, HUNTLEY DA \& DAVIDSON MA. 2004. Physical controls on the dynamics of inlet sandbar systems. Ocean Dyn., 54: 360-373.

SIEGLE E, HUNTLEY DA \& DAVIDSON MA. 2007. Coupling video imaging and numerical modeling for the study of inlet morphodynamics. Mar. Geol., 236: 143-163.

TOLMAN HL. 1997. User manual and system documentation of WAVEWATCH - III version 1.15. NOAA/NWS/NCEP/OMB Technical Note 151, $97 \mathrm{p}$.

TOLMAN HL. 1999. User manual and system documentation of WAVEWATCH - III version 1.15. NOAA/NWS/NCEP/OMB Technical Note 166, $110 p$.

TRUCCOLO EC. 1998. Maré meteorológica e forçantes atmostéricas locais em São Francisco do Sul - SC. Curso de pós-graduação em Engenharia Ambiental. Universidade Federal de Santa Catarina. Dissertação de Mestrado. 100 p.

\section{NOTAS SOBRE OS AUTORES}

Gabriela Freire Cassiano. Oceanógrafa formada pela Universidade do Vale do Itajaí (UNIVALI) em 2005; e Mestre em Oceanografia Geológica pelo Instituto Oceanográfico da Universidade de São Paulo (IO/USP) em 2008. Área de interesse: morfodinâmica costeira.

Eduardo Siegle. Oceanógrafo formado pela Fundação Universidade do Rio Grande (FURG) em 1996; Mestre em Geociências pela Universidade Federal do Rio Grande do Sul (UFRGS) em 1999; e Doutor em Ciências Marinhas pela Universidade de Plymouth (Reino Unido) em 2003. É professor do Instituto Oceanográfico da Universidade de São Paulo desde 2005, onde lidera o grupo de pesquisa em dinâmica costeira. Áreas de interesse: morfodinâmica e circulação costeira. 